\title{
PENILAIAN FASILITAS JALUR PEDESTRIAN DARI ASPEK SAFETY, HEALTH, AND ENVIRONMENT (SHE)
}

\author{
Dinda Fardila ${ }^{1}$, Henricus Priyosulistyo ${ }^{2}$ dan Andreas Triwiyono ${ }^{3}$ \\ 1,2,3 Departemen Teknik Sipil dan Lingkungan, UGM \\ Email: dindafardila@gmail.com
}

\begin{abstract}
Pedestrian way is a space providing services for pedestrian in carrying out their activities. This research aims to evaluate the liability of the pedestrian facilities in complying the prevailing standards and safety, health, and environment (SHE) instead of determining the priority rank for improving the performance of pedestrian facilities. This research was conducted on the pedestrian way of Malioboro area in Yogyakarta, by field survey on 23-27 January 2018. The research used questionnaires with incidental sampling technique. The data was performea and statistically analyzed by SPSS program in terms of Importance Performance Analysis (IPA) method and inference analysis using Rank Spearman's truth test. The result of this research showed that the pedestrian way had generally met the standards (57.14\%) but several facilities (38.10\%) did not meet the criteria and $4.76 \%$ was not available in the pedestrian way of Malioboro. The level of performance of pedestrian facilities based on SHE was mostly high (satisfied). The facilities that must be improved were the cleanliness of the pedestrian way ana the toilet. Some respondences were still able to accept the conditions as follow: the speed of motor bike, the noises, street vendor layout, shop sign layout and the quality of building materials.
\end{abstract}

Keywords: Environment, Importance Performance Analysis (IPA), Pedestrian way, Safety, Health

\begin{abstract}
ABSTRAK
Jalur pedestrian merupakan ruang yang memberikan layanan kepada pejalan kaki dalam melakukan aktivitasnya. Kajian ini bertujuan untuk mengevaluasi kelayakan kondisi fasilitas jalur pedestrian terhadap standar yang berlaku, safety, health, and environment (SHE), dan menentukan prioritas layanan yang diperlukan untuk peningkatan kinerja fasilitas jalur pedestrian. Kajian ini dilakukan pada jalur pedestrian Kawasan Malioboro dengan cara survey lapangan pada tanggal 23-27 Januari 2018. Kajian ini menggunakan kuesioner berskala Likert dengan teknik pengambilan sampel insidental sampling.Analisis data menggunakan analisis statistik deskriptif, metode Importance Performance Analysis (IPA) dan analisis inferensi (uji korelasi Spearman Rank). Hasil kajian menunjukkan bahwa fasilitas jalur pedestrian telah memenuhi standarsebesar $57,14 \%$, tetapi $38,10 \%$ tidak memenuhi kriteria dan $4,76 \%$ fasilitas tidak terdapat di jalur pedestrian kawasan Malioboro. Fasilitas yang harus ditingkatkan kinerjanya pada prioritas utama adalah tingkat kebersihan pedestrian dan toilet. Beberapa pedestrian masih dapat menerima kondisi berikut :kecepatan pengendara bermotor, kebisingan, tata letak PKL, tata letak papan nama toko dan kualitas bahan bangunan.
\end{abstract}

Kata kunci: Environment, Importance Performance Analysis (IPA), Jalur pedestrian, Safety, Health 


\section{PENDAHULUAN}

Kawasan Malioboro terletak di 'jantung kota Yogyakarta' yang berfungsi sebagai pusat pemerintahan dan perkantoran, sekaligus menjadi kawasan tujuan wisata dan tempat perbelanjaan yang paling populer. Berbagai kegiatan masyarakat lokal maupun wisatawan seperti berjalan, berkumpul, berbelanja, dan kegiatankegiatan lainnya sering dilakukan di area ini.

Perkembangan pusat-pusat perdagangan yang sangat pesat di kawasan ini beriringan dengan pertambahan jumlah pengunjungnya. Hal ini mendorong pemerintah untuk menyediakan fasilitasfasilitas pendukung khususnya di area jalur pedestrian Malioboro. Jalur pedestrian merupakan ruang yang dapat memberikan pelayanan untuk pejalan kaki melakukan aktivitas dengan memperhatikan aspek Safety, Health, dan Environment (SHE). Kinerja fasilitas jalur pedestrian dari waktu ke waktu harus dilakukan peninjauan secara berkala agar semakin dibutuhkan untuk memberikan kenyamanan dan semakin menarik pengunjung/ wisatawan. Oleh karena itu dilakukan revitalisasi atau pembaruan terhadap jalur pedestrian yang sudah ada dengan memperhatikan aspek SHE agar fungsi jalur pedestrian dapat lebih optimal bagi penggunanya.

Tujuan kajian ini untuk melakukan evaluasi kelayakan kondisi fasilitas jalur pedestrian di Kawasan Malioboro Yogyakarta berdasarkan peraturan dan standar yang berlaku dan menganalisis dan menentukan prioritas fasilitas jalur pedestrian berdasarkan aspek SHE dalam peningkatan kinerja fasilitas jalur pedestrian. Hasil kajian ini diharapkan dapat menjadi masukan bagi pengelola jalur pedestrian di Kawasan Malioboro memperhatikan kebutuhan pengguna, dan dapat menjadi contoh ideal di tempattempat lainnya.

Evaluasi teknis fasilitas jalur pedestrian Kawasan Malioboro dilaksanakan dengan mengacu pada beberapa peraturan, antara lain :

a. Peraturan Menteri Pekerjaan Umum No. 03/PRT/M/2014 tentang pedoman perencanaan, penyediaan, dan pemanfaatan prasarana dan sarana jaringan pejalan kaki di Kawasan Perkotaan

b. Departemen Perhubungan Tahun 2009 tentang Panduan Penempatan Fasilitas Pelengkap Jalan

c. Peraturan Menteri Perhubungan Nomor 111 Tahun 2015 tentang Penetapan Batas Kecepatan

d. Peraturan Walikota Yogyakarta Nomor 62 Tahun 2009 tentang Perubahan Peraturan Walikota Yogyakarta Nomor 45 Tahun 2007 Tentang Petunjuk Pelaksanaan Peraturan Daerah Kota Yogyakarta Nomor 26 Tahun 2002 Tentang Penataan Pedagang Kaki Lima

e. Peraturan Walikota Yogyakarta Nomor 85 Tahun 2011 tentang Reklame di Bangunan Permanen Pada Kawasan Malioboro Yogyakarta

f. Keputusan Menteri Negara Lingkungan Hidup Nomor 48 Tahun 1996 tentang Baku Tingkat Kebisingan

Jalur pedestrian memiliki fasilitas-fasilitas yang dapat mendukung pedestrian dalam melakukan aktivitas dengan aman dan nyaman. Fasilitas jalur pedestrian menurut Rubenstein (1987) adalah paving, lampu, sign, sculpture, bollard, bangku, tanaman peneduh, tempat istirahat, dan tempat sampah. Fasilitas jalur pedestrian yang baik menurut Departemen Pekerjaan Umum No. 468 Tahun 1998 terdiri dari : (1) jalur pedestrian terletak pada daerah milik jalan, diberi lapisan permukaan, diberi elevasi yang lebih tinggi dari perkerasan jalan, dan pada umumnya sejajar dengan lalu lintas kendaraan (2) penyeberangan dengan fasilitas-fasilitas yaitu jembatan penyeberangan, zebra cross, pelican cross, dan terowongan (3) jalur pelengkap jalur pedestrian yaitu, lapak tunggu, marka, rambu, lampu lalu 
lintas, bangunan pelengkap. Jalur pedestrian yang baik juga harus memiliki kriteria-kriteria yang harus di penuhi guna memenuhi kebutuhan dan keinginan pengguna jalur pedestrian tersebut yaitu sebagai berikut : (1) mudah dicapai (accessibility) oleh semua pengguna (2) lebarnya memadai untuk berjalan (adequate travel with) (3) aman (safety) (4) lancar (continuity) (5) lanscaping (6) ruang sosial (sosial space) (7) ruang yang berkualitas (quality of space).

Fasilitas jalur pedestrian berfungsi untuk mempermudah aktivitas pedestrian serta mendukung kenyamanan dan keamanan saat berjalan kaki. Permen PU Nomor 03/PRT/M/2014 mengungkapkan terdapat beberapa fungsi fasilitas pedestian yang harus dicapai adalah sebagai berikut : (1) jalur penghubung antar pusat kegiatan, blok ke blok, dan persil ke persil di kawasan perkotaan (2) bagian yang tidak terpisahkan dalam sistem pergantian moda pergerakan lainnya (3) ruang interaksi sosial (4) pendukung keindahan dan kenyamanan kota (5) sebagai jalur evaluasi bencana.

Parameter fasilitas Safety, Health, dan Environment (SHE) pada jalur pedestrian biasa digunakan untuk menjaga keamanan, kesehatan dan lingkungan para pekerja disebuah perusahaan. Menurut Zwetsloot (2001), SHE merupakan sebuah sistem yang nyata dan penting bagi banyak organisasi dan sistem ini juga dinilai efektif dalam mengurangi tingkat kecelakaan dalam bekerja. Maka dari itu, dengan adanya fasilitas jalur pedestrian yang berbasis safety, health, and environtment (SHE) akan menaikkan tingkat kepuasan pengguna yang beriringan dengan naiknya nilai investasi pada kawasan Malioboro yang sangat menguntungkan bagi pemerintah daerah. Parameter fasilitas jalur pedestrian berbasis safety, health, and environtment (SHE) yang disajikan pada Tabel 1 adalah sebagai berikut :

a. Safety (Keamanan dan keselamatan) Unterman (1984), faktor keamanan dan keselamatan adalah faktor utama bagi pengguna jalur pedestrian yang merasa aman dengan adanya elemen-elemen pengaman dalam hal ini untuk melindungi pejalan kaki dari berbagai permasalahan yang timbul di jalur pedestrian. Elemen-elemen jalur pedestrian yang masuk dalam aspek safety terdapat pada Tabel 1.

b. Health (Kesehatan dan layanan)

Kesehatan dan layanan disuatu tempat sangat mempengaruhi kenyamanan dan kepuasan seseorang. Hal tersebut berlaku pula pada jalur pedestrian, sehingga penting untuk mengatur elemenelemen jalur pedestrian yang termasuk dalam aspek health yang ditunjukkan pada Tabel 1.

c. Environment (Lingkungan)

Kriteria perancangan ruang untuk pengguna jalur pedestrian yang baik adalah ruang pejalan kaki yang memenuhi tuntutan lingkungan yang baik bagi penggunanya. Pada kajian ini aspek lingkungan hanya akan membahas tentang estetika dan kualitas bahan jalur pedestrian.

Tabel 1 Parameter Fasilitas Jalur Pedestrian

\begin{tabular}{|c|c|c|}
\hline Aspek & No & Parameter Fasilitas Jalur Pedestrian \\
\hline \multirow{8}{*}{ Safety } & 1 & Lebar jalur pedestrian \\
\hline & 2 & Bollard \\
\hline & 3 & Elevasi \\
\hline & 4 & Rambu-rambu \\
\hline & 5 & Pelican Crossing \\
\hline & 6 & Penerangan \\
\hline & 7 & Kecepatan pengendara bermotor \\
\hline & 8 & Fasilitas disabilitas \\
\hline \multirow{4}{*}{ Health } & 9 & Tanaman peneduh \\
\hline & 10 & Kebersihan \\
\hline & 11 & Tempat sampah \\
\hline & 12 & Sirkulasi udara \\
\hline
\end{tabular}




\begin{tabular}{ccl}
\hline Aspek & No & \multicolumn{1}{c}{ Parameter Fasilitas Jalur Pedestrian } \\
\hline \multirow{4}{*}{ Environment } & 13 & Tingkat Kebisingan \\
\cline { 2 - 3 } & 14 & Toilet \\
\cline { 2 - 3 } & 15 & Fasilitas disabilitas untuk kesehatan \\
\hline & 17 & Tempat istirahat \\
\cline { 2 - 3 } & 18 & Tata letak PKL \\
\hline & 20 & Kualitas bahan bangunan \\
\hline & 21 & Tanaman hias \\
\hline
\end{tabular}

\section{METODE}

Lokasi kajian adalah jalur pedestrian di Kawasan Malioboro yang terletak di Jalan Malioboro hingga Jalan Margo Mulyo, Kota Yogyakarta, Provinsi Daerah Istimewa Yogyakarta. Obyek kajian ini adalah jalur pedestrian di ruas timur dan ruas barat jalan, dan terletak tepat di depan pertokoan, perkantoran, atau bangunan lainnya.Obyek kajian dibagi ke dalam beberapa ruas yaitu enam titik pada ruas timur dan enam titik pada ruas barat jalan. Pada Gambar 1 terdapat potongan jalur pedestrian yang berada di depan Hotel Inna Garuda.

Populasi pada kajian ini adalah pedestrian (pejalan kaki) di Kawasan Malioboro Kota Yogyakarta. Sampel kajian ini adalah pedestrian yang sedang berjalan kaki, berhenti, atau melakukan kegiatan pedestrian lainnya di Jalan Malioboro sampai Jalan Margo Mulyo dan bukan pedagang atau pekerja tetap perkantoran atau pertokoan di Kawasan Malioboro. Pengumpulan data menggunakan teknik incidental sampling. Menurut Sugiyono (2017) incidental sampling adalah suatu teknik penentuan sampel yang memilih orang-orang atau kelompok orang yang secara kebetulan ditemui peneliti di daerah kajian dan memenuhi kriteria sebagai sampel kajian. Jumlah sampel ditentukan menggunakan tabel Krecjie dan Morgan dan didapatkan hasil 336 sampel.

Langkah-langkah kajian sebagai berikut:

a. Studi literatur

Melakukan pengumpulan referensirefensi yang relevan dalam kajian ini seperti dasar-dasar teori baik yang bersumber dari buku maupun kajian sejenis dan peraturan-peraturan pemerintah serta standar yang berlaku sebagai acuan dalam pembahasan kajian.

b. Persiapan alat

Membuat formulir survei evaluasi fasilitas jalur pedestrian terhadap standar yang berlaku dan formulir survei evaluasi fasilitas yang tersedia di jalur pedestrian Malioboro untuk pengguna jalur pedestrian. Selain formulir, peneliti menyiapkan alat untuk mendokumentasi gambar berupa kamera dan alat untuk mengolah data berupa laptop yang terdapat software Ms.Word, Ms. Excel, dan SPSS IBM 23.

C. Pengumpulan data

Melakukan pengumpulan data primer yaitu hasil penilaian pedestrian terhadap fasilitas jalur pedestrian kawasan Malioboro, hasil observasi kondisi berupa dokumentasi foto dan hasil penilaian peneliti terhadap standar yang berlaku. Data primer didapatkan secara langsung di lapangan. Data sekunder dalam kajian ini yaitu buku, artikel, jurnal, hasil kajian peraturan-peraturan yang terkait dengan safety, health, dan environment jalur pedestrian dan data inventaris jalur pedestrian di Kawasan Malioboro.

d. Analisis sampling dan pembahasan Setelah data terkumpul, baik data primer maupun data sekunder maka dilakukan rekapitulasi datakemudian menganalisis data tersebut sebagai berikut :
1) Analisis deskriptif terhadap penilaian peneliti terhadap standar.
2) Setelah didapatkan data primer lalu diolah menggunakan analisis

INERSIA, Vol. XIV No. 2, Desember 2018 
Penilaian Fasilitas Jalur ... (Dinda/ hal 133-145)

statistik deskriptif dengan pengukuran mean, modus, tabel frekuensi dan chart data sehingga memperlihatkan jumlah dan proporsi variabel yang digunakan.

3) Importance Performance Analysis (IPA) digunakan untuk mengolah hasil penilaian pedestrian terhadap fasilitas jalur pedestrian dengan skala likert untuk tingkat kinerja/ kepuasan/ performance dan kepentingan. Tahapan pertama yaitu menentukan tingkat kesesuaian antara tingkatkepentingan dan tingkat

kinerja fasilitas. Selanjutnya fasilitas-fasilitas tersebut dijabarkan dan dibagi menjadi empat bagian ke dalam diagram kartesius 4 kuadran. Dalam menganalisis data IPA peneliti menggunakan SPSS IBM 23.

e. Uji Korelasi Spearman Rank dianalisis menggunakan SPSS IBM 23 untuk mengetahui hubungan antara variabel safety, health dan environment jalur pedestrian di Kawasan Malioboro. Tingkat signifikansi sebesar $\alpha=$ $5 \%$ dengan daerah kritik adalah $\mathrm{H}_{0}$ ditolak jika $p$ value<a.

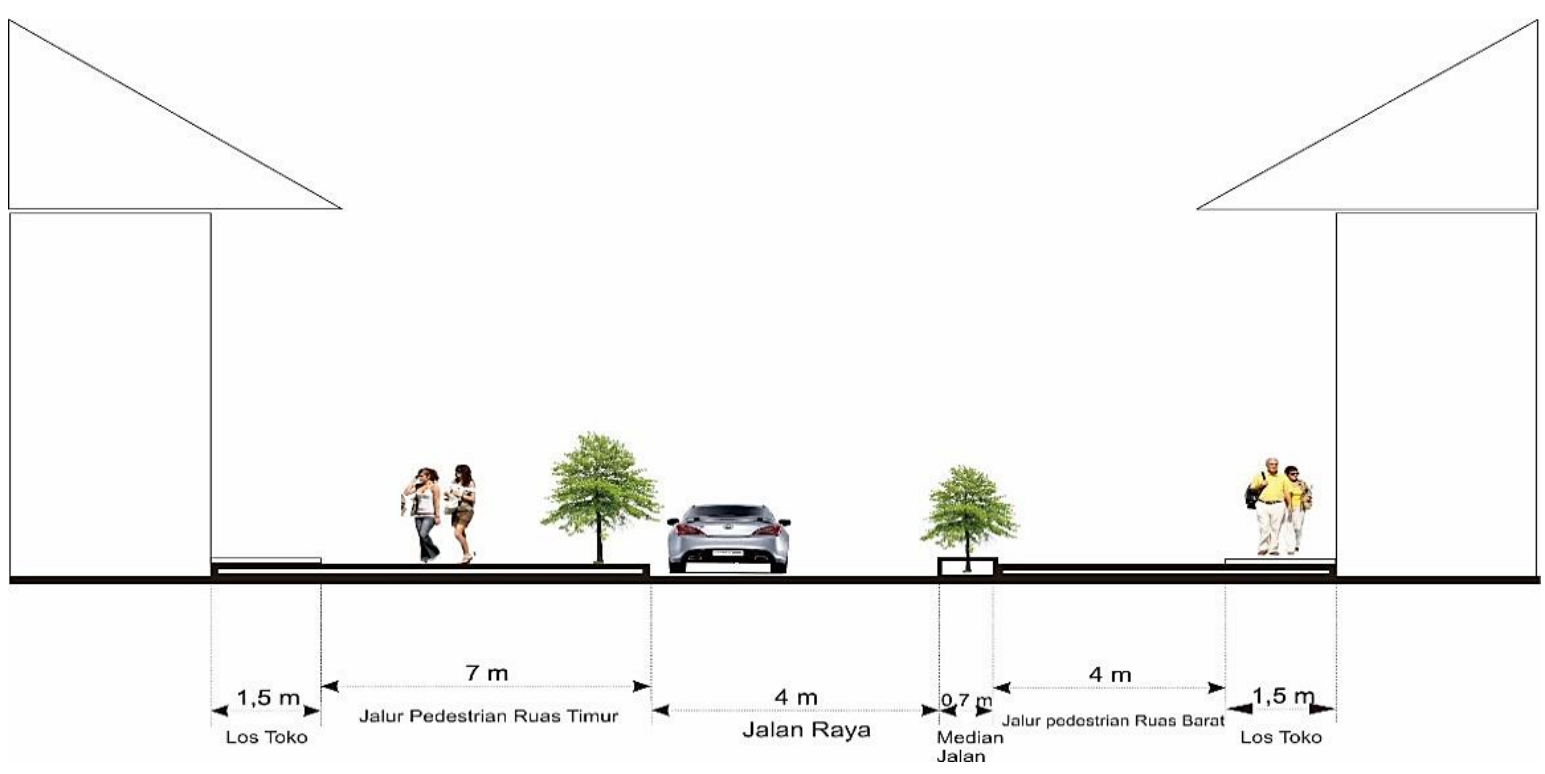

Gambar 1. Potongan Jalur Pedestrian Depan Hotel Inna Garuda

\section{HASIL DAN PEMBAHASAN}

\section{Evaluasi Teknis Jalur Pedestrian Terhadap Standar}

Berdasarkan Tabel 2 hasil evaluasi teknis fasilitas jalur pedestrian Kawasan Malioboro pada aspek safety, health, dan environment terhadap standar yang berlaku diketahui bahwa terdapat sebanyak $57,14 \%$ fasilitas jalur pedestrian yang memenuhi standar yaitu (1) lebar jalur pedestrian (2) bollard (3) elevasi (4) perambuan (5) kecepatan kendaraan bermotor (6) tanaman peneduh (7) tempat sampah (8) fasilitas disabilitas untuk kesehatan (9) tempat istirahat (10) kualitas bahan bangunan (11) fasilitas hiburan, dan (12) tanaman hias.

Sebanyak $38,10 \%$ fasilitas jalur pedestrian yang tidak memenuhi kriteria yaitu sebagai berikut: (1) pelican crossing yang tidak berfungsi dengan baik dari segi 
Penilaian Fasilitas Jalur ... (Dinda/ hal 133-145)

kondisi yang disebabkan kurangnya perawatan dan dari segi kegunaannya yang disebabkan kurangnya sosialisasi terhadap pedestrian (2) penerangan yang belum maksimal karena lampu penerangan terletak di dalam jalur pedestrian dan jarak antar lampu sebesar $30 \mathrm{~m}$ (3) fasilitas disabilitas untuk keamanan berupa jalur khusus difabel dengam material paving block yang bertekstur kasar dan pola timbul tidak terdapat pada jalur pedestrian ruas Barat (4) tingkat kebersihan belum sesuai standar, masih terlihat limbah dari pedagang makanan berceceran karena kurangnya kesadaran pedestrian dan pedagang dalam menjaga kebersihan (5) tingkat kebisingan, dari hasil pengukuran diketahui bahwa tingkat kebisingan pada jalur pedestrian sebesar $75 \mathrm{~dB}$ melebihi standar yang berlaku sebesar $70 \mathrm{~dB}$. Hal ini disebabkan oleh padatnya lalu lintas kendaraan bermotor maupun lalu lalang pedestrian di Kawasan Malioboro terutama pada malam hari (6) toilet yang tesedia sangat minim yaitu dua toilet permanen dan 2 toilet portabel dengan kondisi yang tidak terawat (7) tata letak PKL belum ditata dengan rapi dan dikelompokkan sesuai dengan jenis barang atau jasa yang ditawarkan. Jika ditinjau dari segi estetika ketidakseragaman warna dan material dari lapak PKL juga menambah kesan tidak teraturnya penataan $\mathrm{PKL}$ di Kawasan Malioboro dan (8) tata letak papan nama toko dan reklame yang menutupi ornamen arsitektur atau bahkan menutupi atap bangunan. Hal ini dikarenakan jalur pedestrian ruas Timur telah dilakukan revitalisasi sedangkan ruas Barat belum dilakukan revitalisasi sehingga fasilitasjalur pedestrian di ruas Timur lebih lengkap dan masih dalam kondisi yang baik dan andal.

Terdapat fasilitas yang tidak ada dan tidak memenuhi syarat yaitu sirkulasi udara dengan persentase sebesar $4,76 \%$. Hal ini disebabkannya fasilitas ini tidak memiliki standar yang dapat dijadikan acuan dalam penilaian, sehingga sirkulasi udara pada jalur pedestrian Kawasan Malioboro tidak dapat dikontrol.

\section{Distribusi Karakteristik Responden}

Penilaian dilakukan dengan pengisian formulir survei oleh 336 responden dari pengguna jalur pedestrian Kawasan Malioboro yang penyebaran dibagi menjadi weekday (pagi dan malam) dan weekend (pagi dan malam) sebannyak 84 orang tiap sesi. Karakteristik responden meliputi umur, jenis kelamin, asal, tingkat pendidikan, pekerjaan banyak kunjungan, dan kondisi pedestrian. Berdasarkan hasil perhitungan distribusi karakteristik responden yang terdapat pada Gambar 2 didapatkan hasil bahwa jumlah responden terbanyak pada karakteristik umur antara 15-24 tahun sebesar $73,4 \%$, jenis kelamin didominasi oleh responden laki-laki sebesar $52,1 \%$, asal didominasi oleh responden luar Provinsi DIY sebesar $70,5 \%$, tingkat pendidikan didominasi oleh responden SMA sebesar 54,8\%, pekerjaan didominasi oleh responden pelajar/mahasiswa sebesar 57,4\%, banyak kunjungan didominasi oleh responden dengan kunjungan beberapa kali, dan kondisifisik didominasi oleh responden dengan kondisi fisik normal yakni $93,5 \%$.

Tabel 2 Hasil Evaluasi Teknik Jalur Pedestrian Terhadap Standar

\begin{tabular}{|c|c|c|c|c|c|}
\hline Aspek & No & Fasilitas Jalur Pedestrian & $\begin{array}{c}\text { Ada } \\
\text { dan/atau } \\
\text { Memenuhi } \\
\text { Kriteria }\end{array}$ & $\begin{array}{c}\text { Ada } \\
\text { dan/atau } \\
\text { Tidak } \\
\text { Memenuh } \\
\text { iKriteria } \\
\end{array}$ & $\begin{array}{c}\text { Tidak ada } \\
\text { atau Tidak } \\
\text { Memenuhi } \\
\text { Kriteria }\end{array}$ \\
\hline \multirow{4}{*}{ Safety } & 1 & Lebar jalur pedestrian & V & & \\
\hline & 2 & Bollard & V & & \\
\hline & 3 & Elevasi & V & & \\
\hline & 4 & Rambu-rambu & $\mathrm{V}$ & & \\
\hline
\end{tabular}


Penilaian Fasilitas Jalur ... (Dinda/ hal 133-145)

\begin{tabular}{|c|c|c|c|c|c|}
\hline Aspek & No & Fasilitas Jalur Pedestrian & $\begin{array}{c}\text { Ada } \\
\text { dan/atau } \\
\text { Memenuhi } \\
\text { Kriteria }\end{array}$ & $\begin{array}{c}\text { Ada } \\
\text { dan/atau } \\
\text { Tidak } \\
\text { Memenuh } \\
\text { iKriteria }\end{array}$ & $\begin{array}{c}\text { Tidak ada } \\
\text { atau Tidak } \\
\text { Memenuhi } \\
\text { Kriteria }\end{array}$ \\
\hline & 5 & Pelican Crossing & & $\mathrm{V}$ & \\
\hline & 6 & Penerangan & & $\mathrm{V}$ & \\
\hline & 7 & Kecepatan pengendara bermotor & V & & \\
\hline & 8 & Fasilitas disabilitas untuk keamanan & & $\mathrm{V}$ & \\
\hline \multirow{8}{*}{ Health } & 9 & Tanaman peneduh & V & & \\
\hline & 10 & Tingkat kebersihan & & $\mathrm{V}$ & \\
\hline & 11 & Tempat sampah & V & & \\
\hline & 12 & Sirkulasi udara & & & V \\
\hline & 13 & Tingkat kebisingan & & $\mathrm{V}$ & \\
\hline & 14 & Toilet & & V & \\
\hline & 15 & Fasilitas disabilitas untuk kesehatan & V & & \\
\hline & 16 & Tempat istirahat & $\mathrm{V}$ & & \\
\hline \multirow{5}{*}{ Environment } & 17 & Tata letak PKL & & $\mathrm{V}$ & \\
\hline & 18 & Tata letak papan nama toko & & $\mathrm{V}$ & \\
\hline & 19 & Kualitas Bahan bangunan & $\mathrm{V}$ & & \\
\hline & 20 & Fasilitas hiburan & V & & \\
\hline & 21 & Tanaman hias & $\mathrm{V}$ & & \\
\hline Jumlah & & & 12 & 8 & 1 \\
\hline Persentase & & & $57,14 \%$ & $38,10 \%$ & $4.76 \%$ \\
\hline
\end{tabular}



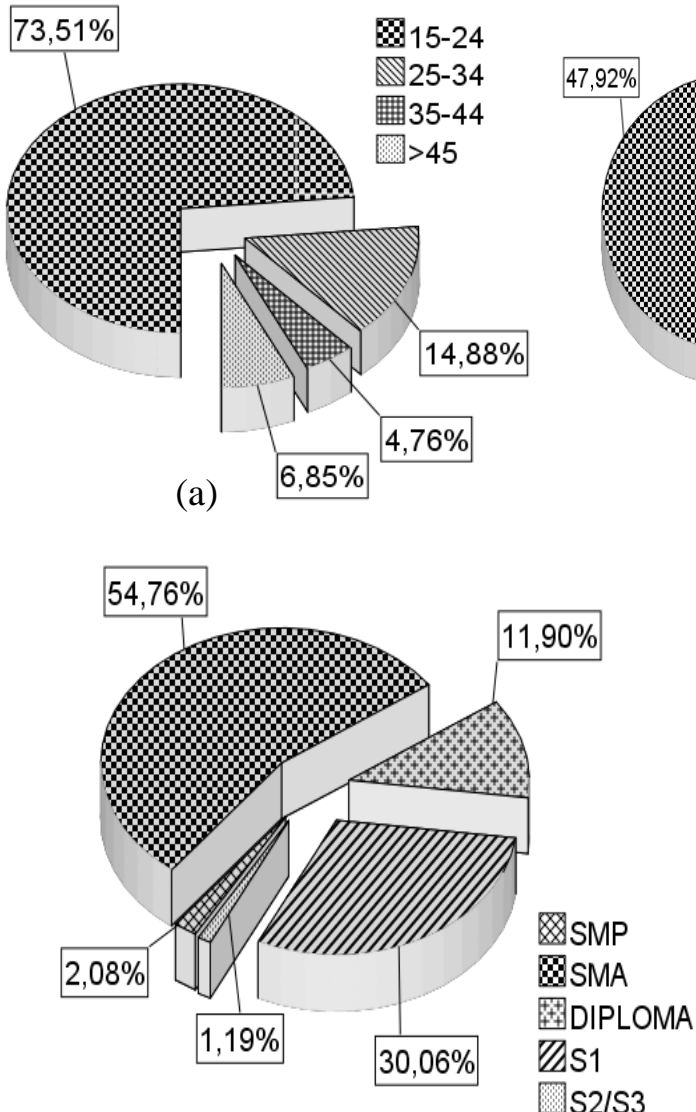

(d)

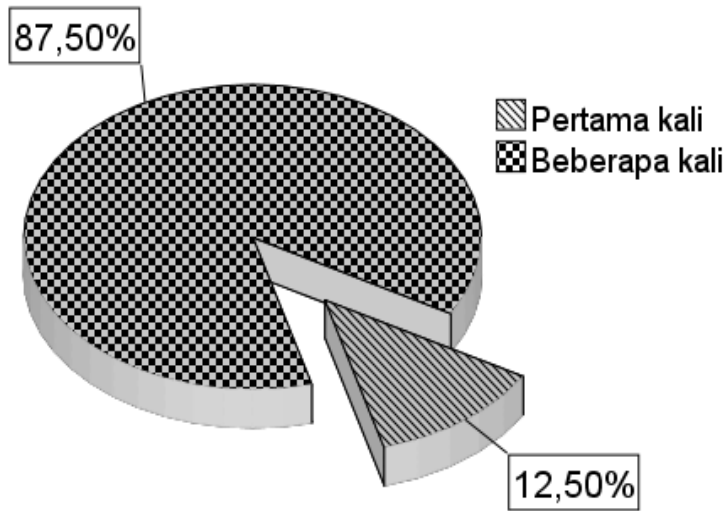

(f)

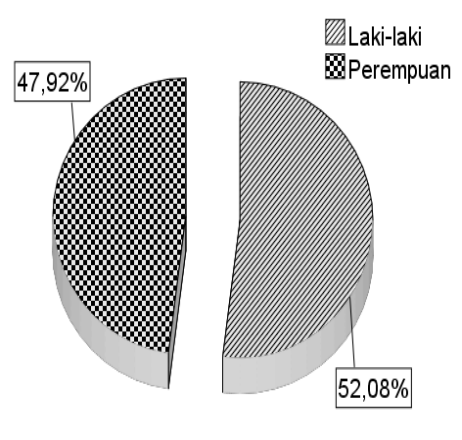

(b)

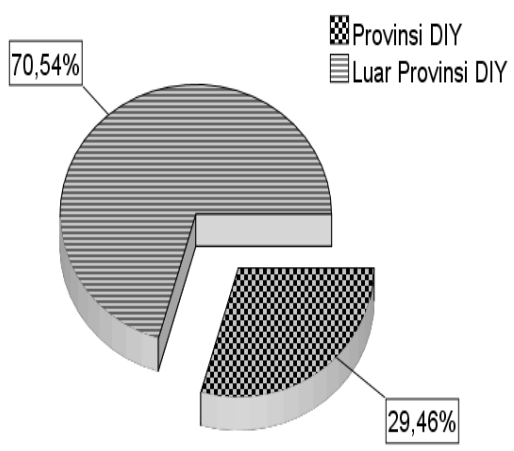

(c)
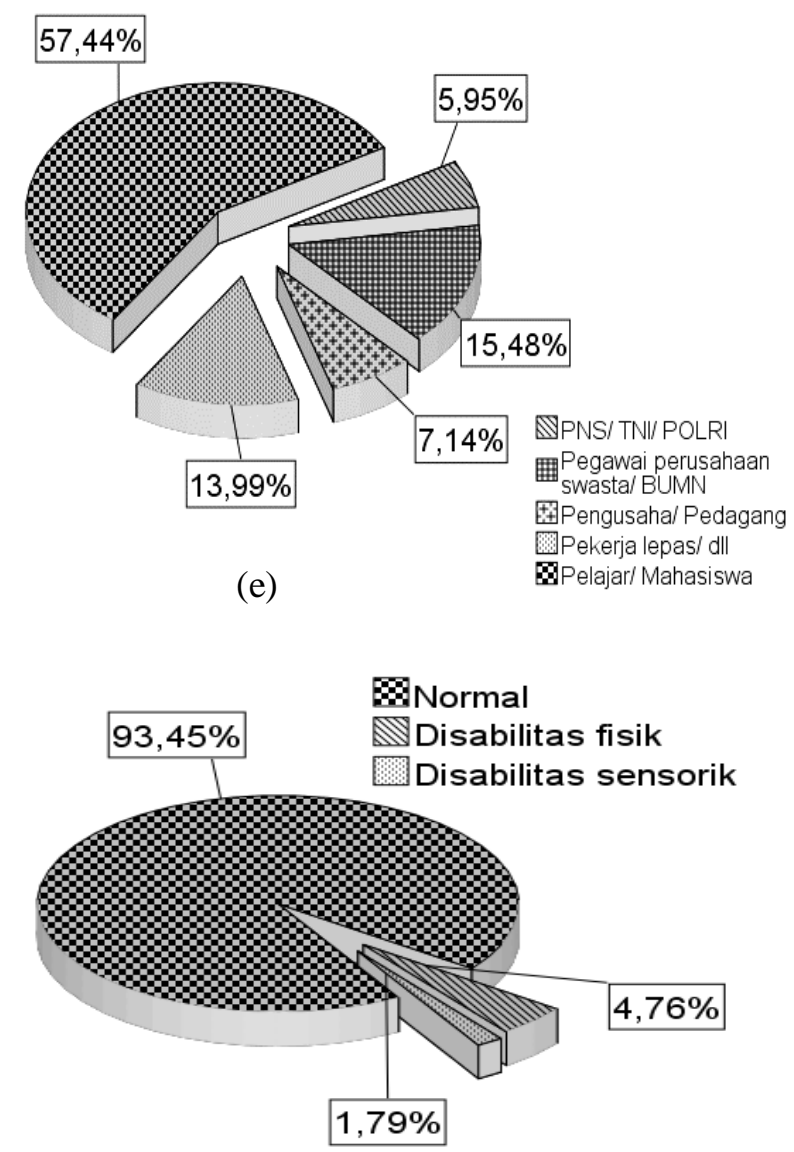

$(\mathrm{g})$

Gambar 2 Distribusi Karakteristik Responden. (a) umur; (b) jenis kelamin; (c) asal; (d) tingkat pendidikan; (e) pekerjaan; (f) banyak kunjungan; (g) kondisi fisik

\section{Importance Performance Analysis (IPA)} Importance Performance Analysis digunakan untuk menentukan urutan prioritas peningkatan kinerja fasiltas-fasilitas yang mempengaruhi kepuasan pedestrian. Analisis dan data survei digambarkan dalam diagram kartesius untuk melihat tingkat importance dan performance dari fasilitas jalur pedestrian tersebut. Tingkat kesesuaian importance dan performance terhadap fasilitas jalur pedestrian untuk mengetahui persepsi pedestrian tentang kepuasan pedestrian terhadap fasilitas di jalur pedestrian Kawasan Malioboro. Berdasarkan Tabel 3 yang menyatakan tingkat kepuasan pedestrian terhadap fasilitas jalur pedestrian, diketahui bahwa $80,95 \%$ fasilitas jalur pedestrian dinilai memuaskan sedangkan $19,05 \%$ dinilai cukup memuaskan. 
Tingkat kepuasan pedestrian fasilitas jalur pedestrian berdasarkan aspek safety termasuk dalam kategori puas kecuali item kecepatan pengendara bermotor masuk dalam kategori cukup puas. Hal ini dikarenakan pedestrian menilai kecepatan pengendara bermotor tergolong tinggi sehingga mengganggu pedestrian dalam beraktifitas terutama saat menyeberang jalan. Perlu adanya sosialisasi tentang peraturan dan pengawasan yang ketat terhadap kecepatan pengendara bermotor untuk meminimalisir ketidakpuasan pedestrian pada jalur pedestrian Kawasan Malioboro. Tingkat kepuasan pedestrian terhadap fasilitas jalur pedestrian berdasarkan aspek health termasuk dalam kategori puas kecuali tingkat kebersihan dan tingkat kebisingan masuk dalam kategori cukup puas disebabkan oleh masih sampah dan limbah yang berserakan dan menumpuk di jalur pedestrian sehingga mengurangi kenyamanan pedestrian dalam beraktifitas. Tingkat kepuasan pedestrian terhadap fasilitas jalur pedestrian berdasarkan aspek environment termasuk dalam kategori puas untuk kualitas bahan bangunan, fasilitas hiburan, dan tanaman hias sedangkan tata letak PKL dan tata letak papan nama toko masuk dalam kategori cukup puas.

Tabel 3 Tingkat Kepuasan Pedestrian Terhadap Fasilitas Jalur Pedestrian

\begin{tabular}{|c|c|c|c|c|}
\hline Aspek & No & Kepuasan terhadap Fasilitas Jalur Pedestrian & Performance & $\begin{array}{l}\text { Tingkat } \\
\text { Kepuasan }\end{array}$ \\
\hline \multirow{8}{*}{ Safety } & 1 & Lebar jalur pedestrian & 3,81 & Puas \\
\hline & 2 & Bollard & 3,74 & Puas \\
\hline & 3 & Elevasi & 3,76 & Puas \\
\hline & 4 & Rambu-rambu & 4,17 & Puas \\
\hline & 5 & Pelican Crossing & 4,12 & Puas \\
\hline & 6 & Penerangan & 4,15 & Puas \\
\hline & 7 & Kecepatan pengendara bermotor & 2,64 & Cukup Puas \\
\hline & 8 & Fasilitas disabilitas untuk keamanan & 3,74 & Puas \\
\hline \multirow{8}{*}{ Health } & 9 & Tanaman peneduh & 3,64 & Puas \\
\hline & 10 & Tingkat Kebersihan & 3,35 & Cukup Puas \\
\hline & 11 & Tempat sampah & 3,80 & Puas \\
\hline & 12 & Sirkulasi udara & 3,63 & Puas \\
\hline & 13 & Tingkat kebisingan & 2,86 & Cukup Puas \\
\hline & 14 & Toilet & 3,52 & Puas \\
\hline & 15 & Fasilitas disabilitas untuk kesehatan & 3,69 & Puas \\
\hline & 16 & Tempat istirahat & 3,77 & Puas \\
\hline \multirow{5}{*}{ Environment } & 17 & Tata letak PKL & 3,23 & Cukup Puas \\
\hline & 18 & Tata letak papan nama toko & 3,41 & Puas \\
\hline & 19 & Kualitas Bahan bangunan & 3,58 & Puas \\
\hline & 20 & Fasilitas hiburan & 3,65 & Puas \\
\hline & 21 & Tanaman hias & 3,90 & Puas \\
\hline \multicolumn{3}{|c|}{ Jumlah Penilaian Puas } & & 17 \\
\hline \multicolumn{3}{|c|}{ Persentase Penilaian Puas } & & $80,95 \%$ \\
\hline \multicolumn{3}{|c|}{ Jumlah Penilaian Cukup Puas } & & 4 \\
\hline \multicolumn{3}{|c|}{ Persentase Penilaian Cukup Puas } & & $19,05 \%$ \\
\hline
\end{tabular}


Pada Gambar 3 terlihat penilaian responden yang termasuk dalam kuadran I menunjukkan bahwa penilaian tersebut dianggap penting dan sangat mempengaruhi kepuasaan pedestrian. Tingkat performance yang telah memuaskan pada aspek safety adalah rambu-rambu, pelican crossing, dan penerangan,. Sementara itu untuk aspek health adalah tempat sampah, sirkulasi udara, tanaman peneduh, fasilitas disabilitas untuk kesehatan, dan tempat istirahat, sedangkan untuk aspek environment adalah tanaman hias. Fasilitas jalur pedestrian yang termasuk dalam kuadran I ini merupakan fasilitas yang perlu dipertahankan oleh pengelola karena kinerjanya telah sesuai dengan kepentingan dan harapan sehingga dapat memuaskan pedestrian. Penilaian responden yang termasuk dalam kuadran II (prioritas utama) menunjukkan bahwa penilaian tersebut dianggap mempunyai tingkat importance yang tinggi dan sangat mempengaruhi kepuasan pedestrian (responden) namun tingkat performance belum memuaskan atau masih rendah hanya pada aspek health adalah tingkat kebersihan dan toilet. Fasilitas jalur pedestrian yang termasuk kuadran II ini membutuhkan penanganan yang harus diprioritaskan peningkatan kinerjanya oleh pengelola.

Penilaian responden yang termasuk dalam kuadaran III (prioritas rendah) menunjukkan bahwa penilaian tersebut dianggap mempunyai tingkat importance yang rendah dan tingkat performance yang tidak memuaskan atau rendah terdapat pada aspek safety adalah kecepatan pengendara bermotor, untuk aspek health adalah tingkat kebisingan, dan untuk aspek environment adalah tata letak PKL, tata letak papan nama toko dan kualitas bahan bangunan. Pedestrian melakukan penilaian tersebut dikarenakanpedestrian merasa pesimis bahwa fasilitas tersebut bisa diatur dengan baik dan sesuai dengan peraturan. Fasilitas jalur pedestrian yang termasuk dalam kuadran III ini membutuhkan penanganan perbaikan oleh pengelola tetapi tidak menjadi prioritas.
Penilaian responden yang termasuk dalam kuadran IV (berlebihan) menunjukkan penilaian tersebut memiliki tingkat importance yang rendah bagi pedestrian. Tingkat performance telah memuaskan sehingga dianggap berlebihan oleh responden pada aspek safety adalah lebar jalur pedestrian, bollard, elevasi, fasilitas disabilitas, dan untuk aspek environment adalah fasilitas hiburan. Fasilitas jalur pedestrian yang termasuk kuadran IV tidak memerlukan peningkatan kinerja karena hanya akan menyebabkan terjadinya pemborosan sumber daya. Hal ini tidak berarti bahwa fasilitas tersebut dianggap tidak penting dan tidak dibutuhkan oleh pedestrian namun kurangnya pengetahuan tentang fungsi fasilitas tersebut dan referensi pedestrian yang minim terhadap contoh jalur pedestrian yang baik dan sesuai standar sehingga menyebabkan pedestrian memberikan penilaian tersebut. Untuk mengatasi hal ini dibutuhkan peran pengelola sekaligus pemerintah daerah untuk memberikan sosialisasi dan pemahaman bagi pedestrian tentang fungsi dari fasilitas yang terdapat pada jalur pedestrian KawasanMalioboro.

\section{Analisis Inferensi}

Pengujian hipotesis pada kajian ini menggunakan teknik analisis Korelasi Rank Spearman dikarenakan variabel pada kajian ini berskala ordinal (non parametrik). Tingkat signifikansi sebesar $\alpha=5 \%$ dengan daerah kritik adalah $\mathrm{H}_{0}$ ditolak jika $p$-value< $\alpha$.

\section{a. Uji Korelasi Pada Performance}

Hipotesis nol $\left(\mathrm{H}_{0}\right)$ dalam kajian ini adalah tidak terdapat korelasi yang signifikan antar variabel performance sedangkan Hipotesis alternatif $\left(\mathrm{H}_{\mathrm{a}}\right)$ adalah terdapat korelasi yang signifikan antar variabel. Dari hasil perhitungan analisis korelasi Rank Spearman seperti ditunjukkan pada Tabel 3 $\mathrm{H}_{0}$ ditolak sehingga ada hubungan antara performance safety, health, dan environment. Jika tingkatkepuasan pada satu variabel meningkat makatingkat kepuasan pada variabel lainmeningkat pula. 
b. Uji korelasi Pada Importance

Hipotesis nol $\left(\mathrm{H}_{0}\right)$ dalam kajian ini adalah tidak terdapat korelasi yang signifikan antar variabel importance sedangkan Hipotesis alternatif $\left(\mathrm{H}_{\mathrm{a}}\right)$ adalah terdapat korelasi yang signifikan antar variabel. Dari hasil perhitungan analisis korelasi rank spearman seperti ditunjukkan pada Tabel $4 \mathrm{H}_{0}$ ditolak sehingga ada hubungan antara performance safety, health, dan environment.Jika tingkat kepuasan pada satu variabel meningkat makatingkat kepuasan pada variabel lainmeningkat pula.

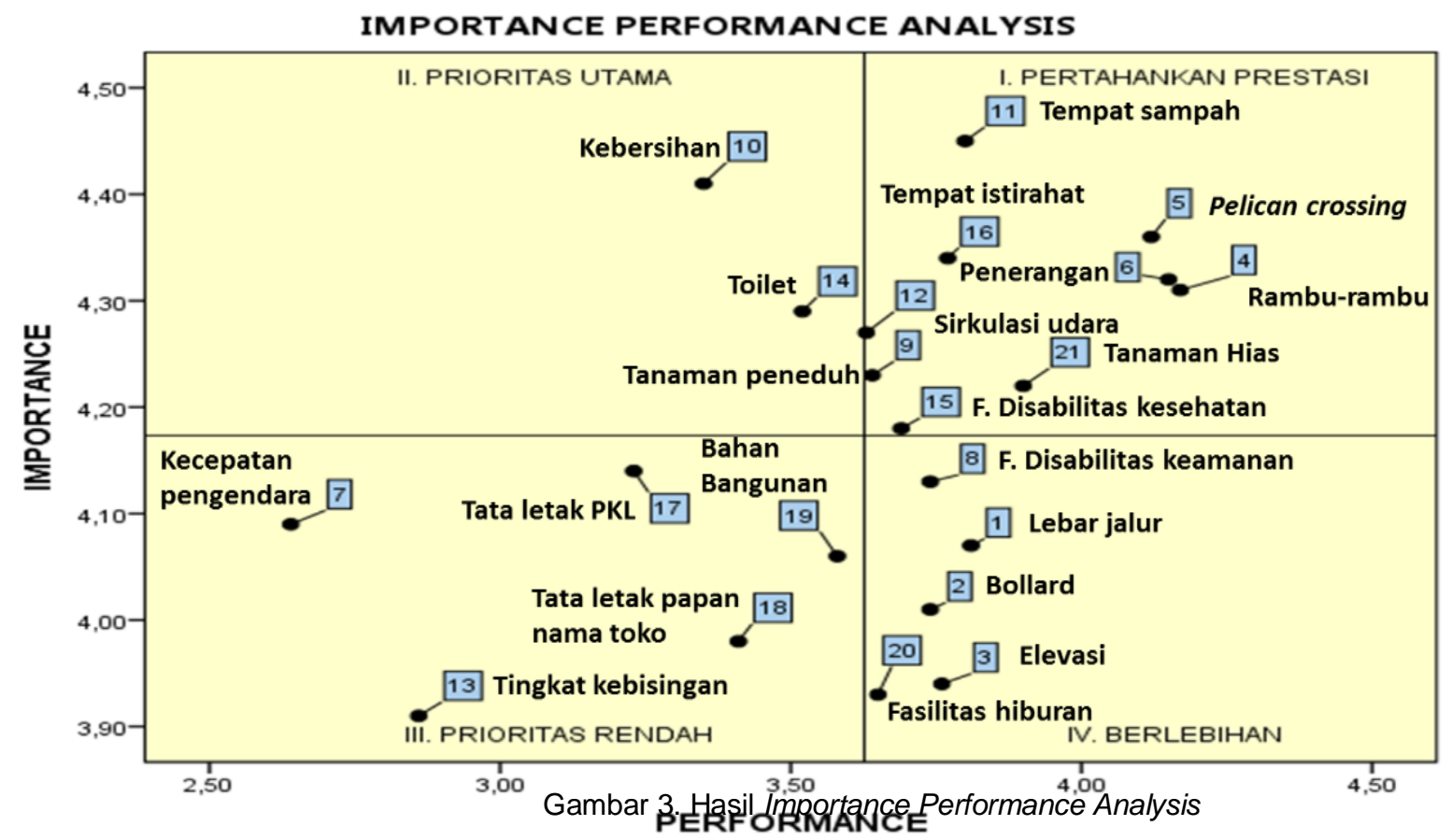

Tabel 3 Hasil Uji Korelasi Pada Performance

\begin{tabular}{clccccc}
\hline No. & Perbandingan Variabel & $\begin{array}{c}\text { Angka } \\
\text { Korelasi (r) }\end{array}$ & $\begin{array}{c}\text { Signifikansi } \\
(\boldsymbol{p} \text {-value) }\end{array}$ & $\begin{array}{c}\text { Koefisien } \\
\text { Determinasi } \\
\text { (KD) }\end{array}$ & Daerah Kritik \\
\hline 1 & Safety & Health & 0.629 & 0,000 & $40 \%$ & $\mathrm{H}_{0}$ ditolak \\
\hline 2 & Safety & Environment & 0.400 & 0,000 & $16 \%$ & $\mathrm{H}_{0}$ ditolak \\
\hline 3 & Health & Environment & 0.580 & 0,000 & $34 \%$ & $\mathrm{H}_{0}$ ditolak \\
\hline
\end{tabular}

Tabel 4 Hasil Uji Korelasi Pada Importance

\begin{tabular}{|c|c|c|c|c|c|c|}
\hline No. & Perba & an Variabel & $\begin{array}{c}\text { Angka } \\
\text { Korelasi (r) }\end{array}$ & $\begin{array}{c}\text { Signifikansi } \\
\text { (p-value) }\end{array}$ & $\begin{array}{l}\text { Koefisien } \\
\text { Determinasi } \\
\text { (KD) }\end{array}$ & Daerah Kritik \\
\hline 1 & Safety & Health & 0.621 & 0,000 & $39 \%$ & $\mathrm{H}_{0}$ ditolak \\
\hline 2 & Safety & Environment & 0.528 & 0,000 & $28 \%$ & $\mathrm{H}_{0}$ ditolak \\
\hline 3 & Health & Environment & 0.668 & 0,000 & $45 \%$ & $\mathrm{H}_{0}$ ditolak \\
\hline
\end{tabular}

\section{SIMPULAN}


Berdasarkan hasil kajian dan pembahasan yang dilakukan, maka dapat disusun beberapa kesimpulan sebagai berikut:

a. $57,14 \%$ fasilitas jalur pedestrian dinilai responden memenuhi standar yaitu (1) lebar jalur pedestrian; (2) bollard; (3) elevasi; (4) perambuan; (5) kecepatan kendaraan bermotor; (6) tanaman peneduh; (7) tempat sampah; (8) fasilitas disabilitas untuk kesehatan; (9) tempat istirahat; (10) kualitas bahan bangunan; (11) fasilitas hiburan; dan (12) tanaman hias.

b. Sebanyak $38,10 \%$ fasilitas jalur pedestrian dinailai responden tidak memenuhi kriteria yaitu (1) pelican crossing; (2) penerangan; (3) fasilitas disabilitas untuk keamanan; (4) tingkat kebersihan; (5) tingkat kebisingan; (6)toilet; (7) tata letak PKL; dan (8) tata letak papan nama toko dan reklame.

c. Terdapat fasilitas yang tidak memenuhi syarat yaitu sirkulasi udara dengan persentase sebesar $4,76 \%$.

d. Pedestrian menilai $80,95 \%$ fasilitas jalur pedestrian Kawasan Malioboro memuaskan sedangkan 19,05\% dinilai cukup memuaskan.

e. Fasilitas yang menjadi prioritas utama untuk dilakukan perbaikan adalahtingkat kebersihan dan toilet dan prioritas kedua (rendah) adalah kecepatan pengendara bermotor, kebisingan, tata letak PKL, tata letak papan nama toko dan kualitas bahan bangunan. Fasilitas yang dinilai responden dalam prioritas keempat (berlebihan) adalah lebar jalur pedestrian, bollard, elevasi, fasilitas disabilitas dan fasilitas hiburan. Prioritas keempat(pertahankan prestasi) adalah rambu-rambu, pelican crossing, penerangan, tempat sampah, sirkulasi udara, tanaman peneduh, fasilitas disabilitas untuk kesehatan, tempat istirahat dan tanaman hias.

f. Terdapat hubungan yang signifikan antara aspek safety, health, dan environment pada performance dan importance sehingga jika tingkat kepuasan pada satu variabel meningkat maka tingkat kepuasan pada variabel lainmeningkat pula.

\section{DAFTAR RUJUKAN}

Carr, S., Francis, M., G. Rivlin, L and M. Stone, A. 1992. Public Space. Cambridge :Cambrige University Press

$\begin{array}{cr}\text { Departemen } & \text { Perhubungan. } \\ \text { Departemen Perhubungan Tahun } \\ 2009 \text { tentang Panduan Penempatan } \\ \text { Fasilitas Pelengkapan Jalan. Jakarta } \\ \text { :Departemen Perhubungan }\end{array}$

Departemen PU. 1998. Departemen Pekerjaan Umum No. 468 Tahun 1998 tentang Tata Cara Perencanaan Fasilitas Pejalan Kaki. Jakarta :Departemen Pekerjaan Umum

Menteri Negara Lingkungan Hidup. 1996. Keputusan Menteri Negara Lingkungan Hidup No. 48 Tahun 1996 tentang Baku Tingkat Kebisingan. Jakarta: Kementerian Negara Lingkungan Hidup

Menteri Perhubungan. 2015. Peraturan Menteri Perhubungan Nomor 111 Tahun 2015 tentang Penetapan Batas Kecepatan. Jakarta :Kementerian Perhubungan

Menteri PU RI. 2014. Peraturan Menteri Pekerjaan Umum Nomor: 03/PRT/M/2014 tentang Pedoman Perencanaan, Penyediaan, danPemanfaatan Prasarana dan Sarana Jaringan Pejalan Kaki di Kawasan Perkotaan. Jakarta :Kementerian Pekerjaan Umum Republik Indonesia.

Prihadi, W. R., \& Pratama, G. N. I. P. Konfigurasi Batang Pada Perancangan Rangka Atap Bambu. INERSIA, 12(2), 173-183.

Rangkuti, F, 2002. Measuring Customer Satisfaction Teknik Mengukur dan Strategi Meningkatkan Kepuasaan Pelanggan. Jakarta: PT. Gramedia Pustaka Utama.

Rubenstein, H. M. 1987. A Guide to Site and Landscape Construction 
Planning. New York :John Wiley \& Sons, Inc

Sugiyono. 2017. Statistika untuk Kajian Cetakan Ke-28. Bandung :Alfabeta

Untermann, R. K. 1984. Accomodating the Pedestrian. New York :Van Nostrand Reinhold Company

Walikota Yogyakarta. 2009. Peraturan Walikota Yogyakrta Nomor 62 Tahun 2009 tentang Perubahan Peraturan Walikota Yogyakarta Nomor 45 Tahun 2007 Tentang Petunjuk Pelaksanaan Peraturan Daerah Kota Yogyakarta Nomor 26 Tahun 2002 Tentang
Penataan Pedagang Kaki Lima. Yogyakarta :Walikota Yogyakarta.

Walikota Yogyakarta. 2011. Peraturan Walikota Yogyakarta Nomor 85 Tahun 2011 tentang Reklame di Bangunan Permanen Pada Kawasan Malioboro Yogyakarta. Yogyakarta: Waliokota Yogyakarta

Zwetsloot, G. 2001. The Management of Innovation by Frontrunner Companies in Environmental Management and Health and Safety, Environmental Management and Health, Vol. 12, No. 2, pp. 207-214. 